\title{
Pensamiento, historia y acción en Baroja
}

\author{
Esteban ANTXUSTEGUI IGARTUA
}

Universidad del País Vasco/EHU

RESUMEN. Coincidiendo, más o menos, con el cincuentenario de la muerte de Pío Baroja (1956), este artículo pretende acercarse al modo con que el escritor se enfrentó al hecho histórico. De la mano de su histórico y recreado pariente Eugenio de Aviraneta, el activista héroe de los veintidós tomos de las «Memorias de un hombre de acción», Pío Baroja, animado por un estímulo esencialmente intelectual, se adentra en la historia, entendida como educación del pensamiento que, dice Baroja, explica el presente y predispone para el futuro. En este viaje, que transcurre desde 1912 a 1934, y usando los instrumentos que la literatura posee para expresar el pensamiento, Pío Baroja realiza una profunda reflexión, siempre relativizado por su pesimismo y escepticismo, sobre una generación de la historia de España, capaz de esclarecer lo español.

Palabras clave: Baroja, Aviraneta, escepticismo, liberalismo, literatura y moral, pesimismo.
Abstract. More than fifty yers after Pío Baroja passed away (1956), this paper aims to examine Baroja's idea of history. Through the personal experiences of his historial but recreated character Eugenio de Aviraneta, the hero of the twenty-two volumes of his Memories of a Man of Action, Baroja explores Spanish history. Moved by an essentially intellectual stimulus, Baroja holds history educates thought, explains the present and anticipates the future. In this journey, that lasts from 1912 to 1934, Baroja makes use of the resources literature enjoys to express thought. The result is a profound reflection, always relativized by his pessimism and his skepticism, on a generation capable of clarifying the meanings of the history of Spain.

Key words: Baroja, Aviraneta, scepticism, liberalism, literature and morals, pessimism.

«El hombre de acción es el que cree que obra exclusivamente por sus propias inspiraciones, el que afirma más su albedrío, el que escoge lo que debe hacer y no debe hacer, $y$, sin embargo es el que está más sujeto a la ley de fatalidad, que marcha más arrastrado por la fuerza de los acontecimientos» (Pío Baroja)

Los aniversarios, las efemérides, son una oportunidad para jugar con el pasado y el presente de las grandes aportaciones creativas, un buen momento para vivir la experiencia intelectual de comprender el mundo exterior reduciendo a su complejidad una especie de representación más o menos ordenada.
Baroja es uno de los escritores fallecidos que mejor salud presentan. Medio siglo después de su muerte, sus obras se siguen reeditando, sigue siendo leído y sigue resultando controvertido. Porque Baroja enseña a mirar. Lo accidental, lo anecdótico, lo que durante unos segundos apareció ante nuestros ojos y que jamás 
volveremos a ver es lo que Baroja quiere rescatar. La obra de Baroja es esencialmente fragmentaria, inacabada, como lo son todas las vidas.

También es evidente que Pío Baroja tuvo especial empeño en no cortar el cordón umbilical que une su literatura a sus propias experiencias. Así lo confiesa en sus Memorias, donde, en El escritor según él y según los críticos, dice:

"Yo no he partido nunca de la lectura de un libro para escribir otro (...). Yo he escrito de la vida pobre de Madrid porque la casualidad me hizo conocerla; he contado la vida de un médico de aldea porque he sido médico de pueblo; he hablado de la guerra carlista del 73 al 76 porque mi padre estuvo en ella. He escrito de Aviraneta porque era pariente mío, y he hablado de la brujería vasca porque vivo cerca de un foco de brujería» ${ }^{1}$.

\section{Baroja y la historia}

Este gusto por contar le acercó a la historia, a las cosas que fueron, aunque siempre desde una posición muy distante de otras que pudiéramos llamar académicas. En La caverna del humorismo ya sentencia que no hay gran diferencia entre la historia y la novela, señalando incluso que la historia es una rama de la literatura. En este sentido, reivindica escribir una historia desde el plano no profesional, manifestando su oposición a la historia tal como la conciben los estudiosos de origen universitario.

La cuestión, según, Baroja, está en cómo enfrentarse al hecho histórico, suceso ante el que se puede reaccionar agrandándolo o empequeñeciéndolo. Baroja, evidentemente, no se podía limitar a recoger de manera convencional lo que habían cultivado y aportado al género de la novela histórica autores como el escocés Walter Scott, el ruso León Tolstoi o, en el caso español, Benito Pérez Galdós con sus Episodios Nacionales. Igualmente, tampoco podía repetir mecánicamente el patrón de la novela histórica decimonónica. Como acertadamente señala el profesor C. A. Longhurst, «tanto el temperamento como la orientación artística de Baroja le habrían impedido aceptar el patrón decimonónico de la novela histórica (...) el concepto barojiano de la novela histórica está más cerca de la concepción modernista de la literatura (...) que de la concepción realista decimonónica» (1988, 155).

Baroja ve en la historia una educación del pensamiento, un entrenamiento que explica el presente y predispone hacia el futuro, pero que no acarrea una enseñanza moral. La historia, para Baroja, no es el ámbito de la moral, es una derivación de la literatura, donde tiene más interés percibir el fragmento y el detalle que conocer globalmente un suceso, porque entiende que los acontecimientos no son más que el brillo de los peldaños que pisamos, mientras que los minúsculos sucesos que acaecen sin ningún realce son la materia de la que están hechas las escaleras que utilizamos en nuestro ascenso o descenso.

Baroja no escribe con la pretensión de hacer accesible la síntesis histórica de cada episodio, algo que, además, él mismo reconocía que no alcanzaba a comprender. Baroja estaba empecinado por la determinación de ser auténtico y fiel a sí mismo en todo momento y circunstancia. Él, que poco años antes que morir afirmó que «yo hubiera aceptado como lema: la verdad siempre, el sueño en su esfera», entendía indispensable la verdad ante todo y para todo, la honestidad antes que nada.

Baroja, sobre todo, quería emanciparse de los frenos indicados por la santurronería y siempre se opuso a los convencionalismos que determinadas maneras acomodadas de vivir pretendían implantar. Con este norte, al encararse con el pasado 
y con la historia, indagó vehementemente tratando de buscar restos que aportaran pistas verdaderas de lo que ocurrió, fragmentos que, por insignificantes que parecieran, acreditaran detalles de lo acontecido.

Ante la imposibilidad, y la inutilidad, de aprehender la historia, Baroja, como Maquiavelo, no se preocupa por hacer una historia respetuosa con los hechos, sino que se contenta con extraer de ella acontecimientos que inspiren principios de acción práctica. Convierte la historia en historias, y en vez de hablarnos de narraciones destinadas a ser maestras en nuestra vida, habla de las maestras de nuestras acciones.

Los veintidós tomos de las Memorias de un hombre de acción, sobre la vida y las andanzas de Eugenio de Aviraneta, publicados por Baroja entre 1912 y 1934 , constituyen el «ciclo histórico», donde el activismo impregna toda la obra e impulsa a su héroe, Aviraneta, fiel devoto de aquella máxima de Boccacio: «es mejor actuar y arrepentirse, que no actuar y arrepentirse igualmente (é meglio fare $e$ pentirse che non fare e pentirsi)».

En este sentido, los personajes históricos barojianos considerarán las distintas acciones y elecciones trágicas en las que estarán embarcados desde la perspectiva de las consecuencias que se derivan de uno u otro curso de la acción, y no desde su ajuste a determinados principios morales. Baroja nunca pretenderá forzar las cosas para intentar que sean "como deben ser», pues lo único que se logra es la propia ruina a causa de una rigidez que impide a los hombres adaptarse a la variabilidad infinita de los acontecimientos. Naturalmente, esto no implica un relativismo que impida aprender de sucesos históricos del pasado propio o ajeno. Las historias siempre nos permiten aprender y aplicar lo aprendido a nuestros propios tiempos ya que, desde siempre, los seres humanos han manifestado y manifiestan las mismas pasiones. Es, por tanto, a partir de ciertos ejemplos, constantemente repetidos en el devenir histórico, como podemos formular principios generales que nunca perderán su utilidad.

Volviendo a la cuestión de determinar si existe un ámbito moral o de otro tipo capaz de frenar «exteriormente» los abusos en la historia, capaz de funcionar como una suerte de límite objetivo y superior, haciendo referencia a la existencia de ámbitos independientes del contexto y que sirvan de freno al mal, la respuesta barojiana sólo puede ser: creo que no.

Porque el problema no es creer sino crear. No existen otros mundos, aunque existen otros países; no hay ámbitos éticos o morales separados del mundo e indestructibles, aunque existan siempre alternativas morales, pero puede que, si trabajamos bien, exista la voluntad de crear esos mundos desde el aquí y el ahora, desde lo concreto en el que vivimos. De re-crear esos otros mundos con nuestros actos, con nuestras palabras, con nuestras reflexiones. Y hay una enorme diferencia, que va más allá de una letra, entre creer y crear, porque ahora de lo que hablamos es de una apertura a la reflexividad que permita educar constantemente nuestra sensibilidad moral y política, y elaborar con espíritu crítico y autonomía nuestro nivel de tolerabilidad de los medios de acción trágica. Los límites de lo tolerable no están ahí, dados por nosotros, son nuestra propia creación: nosotros trazamos la línea de lo intolerable. Y no lo hacemos sólo en el discurso del deber ser, sino, sobre todo, a través de la acción. Por eso, a través de un personaje de acción como Aviraneta, Baroja podía verter uno de los componentes de su identidad, relegado a la penumbra por las circunstancias de la vida. El escritor, que antes de los treinta años ya había decidido dedicarse enteramente a la literatura, 
ya tenía su personaje, sobre el que volcar los estímulos que nutrían su espíritu intrépido y fantástico. En las horas solitarias de 1918 confesaba Baroja: «La acción por la ambición y el placer me parece poca cosa. A mí me gustaría la acción, la gimnasia del espíritu, la superación de mí mismo, pero no por placer, sino por un sentimiento de orgullo.»

\section{La novela histórica barojiana}

Como afirma Francisco J. Flores Arroyuelo (1971: 352-354), hay un extraordinario paralelismo entre el sentido histórico de Tolstoi y Baroja. Nuestro escritor leyó repetidas veces Guerra y paz, de donde extrajo numerosas enseñanzas sobre la cuestión de cómo enfrentarse con el pasado. Asimismo, en el panorama español, Baroja tuvo que enfrentarse al legado de la novela histórica de Pérez Galdós, autor por el que no sintió demasiada simpatía, e incluso la obra histórica barojiana supone en gran parte un consciente alegato contestatario a los Episodios nacionales de aquél.

El propio Baroja apunta una serie de distinciones entre su obra y la manera de concebir el pasado español del siglo XIX contrapuesta a la reflejada por Pérez Galdós: "Galdós ha ido a la historia por afición a ella; yo he ido a la historia por curiosidad hacia un tipo; Galdós ha buscado los momentos más brillantes para historiarlos, yo he insistido en los que me ha dado el protagonista. El criterio histórico también es distinto: Galdós pinta a España como un feudo aparte; yo la presento muy unida los movimientos liberales y reaccionarios de Francia; Galdós da la impresión de que la España de la guerra de la Independencia está muy lejos de la actual; yo casi encuentro la misma de hoy, sobre todo en el campo. Como investigador, Galdós ha hecho poco o nada: ha tomado la historia hecha en los libros; en este sentido, yo he recorrido los lugares de acción de mis novelas, intentando reconstruir lo pasado. Artísticamente, la obra de Galdós parece una colección de cuadros de caballete de toques hábiles y de colores brillantes; la mía podría recordar grabados en madera hechos con más paciencia y más tosquedad» ${ }^{2}$.

El mismo Baroja confiesa en sus Memorias (El escritor según él y según los críticos) que «yo no me he propuesto escribir novelas históricas. No. A mí lo que me ocurre es que me encontré con un personaje, pariente mío, que me chocó, me intrigó y me produjo el deseo de escribir su vida de una manera novelesca. Yo no quise hacer novelas de aire heroico, sino recoger datos de una vida y romancearla».

Baroja, por tanto, fue hacia la historia animado por un estímulo esencialmente intelectual, siempre relativizado por su pesimismo y escepticismo. Además, para historiar Baroja advertía dos propósitos, fronterizos entre sí, pero inalcanzables a la vez: por un lado, pretendía relatar una historia, y recrear una secuencia de hechos que habían acaecido y que se habían desvanecido; y para ello no tenía más opción que investigar, rastrear, localizar, reunir, seleccionar, estructurar los datos y exponerlos convenientemente; y por otro lado, había que acometer una labor de elaboración, capaz de representar y transmitir la impresión del espacio y del tiempo en que se había penetrado, erigiendo un acabado cuadro provisto de detalles y descripciones que fuesen arropando lo historiado, y en el que tuvieran aforo desde los instantes de pasión hasta los monótonos momentos de lo cotidiano.

En este sentido, lo que de verdad mueve la pluma de Baroja es la ocasión que el tipo y su aventura y la época le prestan para recrear un complejo y vasto universo novelesco típicamente «barojiano», novelas de acción y de aventuras, 
más que «memorias», en el sentido literario específico del término. La autenticidad de Baroja es novelesca más que histórica $\mathrm{y}$, de establecer una comparación entre el tratamiento que ambos autores dan a la figura del conspirador, ésta tendría que hacerse no con las Memorias de un hombre de acción, sino con el libro biográfico, histórico y documental Aviraneta o la vida de un conspirador, publicado por don Pío en 1931. Como muy bien señala Longhurst (1974, 81): «... las normas que debemos aplicar a la obra de Baroja son al fin y al cabo las de un novelista, no las de un historiador».

\section{Estrategias narrativas}

en Las Memorias de un hombre de acción

Para encadenar el trama de los diversos volúmenes que habían de componer las Memorias de un hombre de acción, Baroja se escudó tras el nombre de don Pedro Leguía y Gastelumendi, ficticio pariente suyo, atribuyéndole el papel de redactor de los cuadernos de las Memorias, y dejando para sí el más leve de corrector de algunos datos y el de explicador de los pasajes que pudieran parecer más oscuros. Además, está el propio personaje de Eugenio de Aviraneta, que en el texto será en ocasiones también uno de los múltiples narradores que se introducen, cuando cuenta retazos de su vida a Leguía, o cuando éste se limita a transcribir diarios, crónicas, etc., del propio Aviraneta.

A través de este complicado juego, Baroja pretende justificar no ya la veracidad del personaje - nadie pone en duda la historicidad de Aviraneta-, sino la veracidad también del relato de su vida y de sus aventuras, relato hecho por una persona próxima al personaje, como es Leguía. Baroja le «presta» a Leguía su saber objetivo sobre Aviraneta y además algu- nos documentos, textos del propio Aviraneta, que Leguía «debe utilizar» en su crónica; pero, aparte de esto, Leguía tiene sobre Aviraneta otras fuentes de conocimiento que Baroja «no habría podido» tener, como son los relatos orales que le hace el propio Aviraneta, ya que es su contemporáneo y amigo, algo que no es Pío Baroja. Leguía no le habría podido servir a Baroja para escribir la biografía, la historia de Aviraneta. Sí le sirve para transponer el discurso sobre Aviraneta del plano histórico al plano de la ficción.

De todos modos, Leguía, en cuanto criatura de Baroja, está hecho a su imagen y semejanza; tiene sus cualidades, sus ideas, sus aficiones, sus manías y, sobre todo, escribe como él, a pesar de que Baroja se haya visto obligado a corregir algunos excesos retóricos del estilo de don Pedro. Si Leguía es el puente que le permite a Baroja llegar hasta Aviraneta, entrar en relación con él, se trata, en todo caso, de una relación dialéctica y hasta polémica; porque Leguía, a pesar del gran respeto que siente por Aviraneta, por «Don Eugenio», disiente a veces de él, discute, le contradice; Leguía proyecta en el discurso la actitud crítica de Pío Baroja hacia la figura histórico/novelesca de Aviraneta.

En definitiva, Baroja se sirve de Leguía para transferir a Aviraneta del plano de la historia, en el sentido estricto del término, al de la ficción. Leguía es la garantía de la naturaleza novelesca de don Eugenio de Aviraneta en las Memorias; porque al poner a un ente de ficción como Leguía como garante de la veracidad, y no de la mera verosimilitud, de lo narrado, haciendo de él amigo y confidente de Aviraneta, destinatario de sus relatos orales, depositario de crónicas o cuadernos de otros personajes, o insistiendo en que es él el «verdadero» cronista de las memorias de Aviraneta, Baroja, por una especie de «reducción narrativa al absur- 
do», convierte la historia en ficción, o mejor, subordina lo histórico a lo ficticio, sometiéndolo a las leyes de la novela y haciéndolo funcionar en un sistema novelesco y no histórico.

El mismo Baroja, en el prólogo de $E l$ aprendiz de conspirador, concluye sobre los resultados de su estrategia narrativa, en una cita no exenta de humor: «A la hora ya casi no sé lo que dicto Aviraneta, lo que escribió Leguía y lo que he añadido yo; los tres formamos una pequeña trinidad, única e indivisible. Los tres hemos colaborado en este libro: Aviraneta, contando su vida; don Pedro Leguía, escribiéndola, y yo, arreglando la obra al gusto moderno, quizá estropeándola».

\section{El trabajo de documentación}

Para Baroja la historia se presentaba como una necrópolis de huesos, cenizas y restos de poco valor, donde la verdad tenía muy pocas posibilidades de brillar. Ante estos desechos, al historiador/novelista sólo le quedaba un recurso: dejar que su imaginación fluyera en libertad sobre los datos verdaderos, aquellos que, aunque fragmentarios, su razón y su lógica había logrado reunir.

Y para descubrir estos datos, mejor dicho, para informarse sobre estos datos, Baroja se sirvió de cuantiosos elementos ambientales, y rastreó intensamente tras las costumbres, conductas y estilos de vida que pudieran reflejar la vida cotidiana del período analizado. Igualmente hizo uso de las fuentes pictóricas que le brindaban los cuadros, recorrió pacientemente los museos para escudriñar entre los objetos que guardaban sus vitrinas, y se sirvió de la colección de grabados y estampas que fue reuniendo a lo largo de sus numerosas visitas a las librerías de viejo de muchas ciudades.

Otra fuente de información fueron, evidentemente, los archivos, donde repo- saban documentos y referencias valiosas que pretendía rescatar. En sus frecuentes idas y venidas a estas galerías de papel le ocurrieron muchos incidentes, y no puedo evitar reproducir el siguiente relato de Pío Baroja, donde, con ironía y sarcasmo, nos cuenta su visita a los archivos para encontrar documentos sobre Aviraneta («Prólogo», Aviraneta o la vida de un conspirador):

«No deja de ser curioso que en un país como España, en donde se ha ensalzado a tanto personaje huero, sin valor, sin energía y sin inteligencia, se persiga con la antipatía hasta después de muerto a un hombre como Aviraneta, de gran valor, de gran inteligencia y de gran probidad.

En vista de que no encontraba datos, visité varios archivos, y después de dar muchas vueltas, encontré la hoja de servicios de Aviraneta en el Archivo de las Clases pasivas.

El encuentro tuvo algunos incidentes graciosos. Me había dado un amigo dos cartas: una para el subsecretario de Gobernación y otra para el de Hacienda. Fui al ministerio de la Gobernación. El subsecretario me recibió muy amable, como hombre que sabe tratar a los literatos de manera familiar y campechana. Oyó lo que le decía, es decir, no sé si lo oyó, porque los políticos españoles no se toman el trabajo de oír, y llamó al timbre. Apareció un empleado.

- Vaya usted al Archivo con el señor Baroja y pregunte por el señor Tal, por el señor Cual, por cualesquiera de los archiveros, y dígales que sirvan al señor Baroja.

Salimos el empleado y yo del despacho del subsecretario y llegamos al Archivo, en donde, al llamar, se presentó el portero.

— ¿Está el señor Tal? — preguntó el empleado que me acompañaba.

-No, señor; no está en Madrid.

—EEl señor Cual?

- Acaba de salir ahora mismo. 
—¿Don Fulano?

— Tiene la mujer mala y no viene.

- ¿Don Zutano?

— Tampoco está.

El empleado me miró fríamente, como diciendo: "Puede usted hacer lo que guste". Y se marchó.

- Mire usted — dije al portero-, yo quisiera ver si aquí hay una documentación de un tal Aviraneta.

-Aviraneta, la A está allá arriba -me dijo, mostrándome un aparador muy alto-. No se puede subir. lera?

— ¿Pero no habrá por aquí una esca-

Había una escalera. La cogí y la puse en la pared. El portero subió al estante y echó al suelo un legajo lleno de polvo. Lo miré con cuidado. Nada.

A los ocho o diez días fui al ministerio de Hacienda; nueva escena por el estilo, hasta que me enviaron a una oficina de patio. Allí, un viejo empleado me dijo:

-Vuelva usted dentro de quince días.

- Volví, el viejo me dio una nota que ponía: "Aviraneta, Eugenio: Archivo de Clases Pasivas".

Marché al Archivo de Clases Pasivas, y comenzaron otra vez las dificultades.

El archivero me advirtió que no se podían ver los legajos, yo le expliqué que no se trataba de obtener ninguna pensión, sino de un estudio histórico; hizo como que me oía, y me dijo que volviera dentro de quince días.

Volví, y el archivero no estaba, no había más que un mozo. Le expliqué lo que me había prometido el archivero; el mozo sacó un cuaderno y me preguntó:

- ¿En qué fecha murió ese señor? busco.

—No lo sé a punto fijo; es lo que

—Cómo se llamaba?

-Aviraneta e Ibargoyen, Eugenio.

El mozo repasó el cuaderno muy serio, y me dijo:

—No está.
- ¿Usted quiere dejarme ver el cuaderno? -le pregunté.

—Véalo usted si quiere. Es inútil; no está.

Cogí el cuaderno, y en la primera página, en la primera línea ponía: Eugenio de Aviraneta e Ibargoyen.

—Pues está aquí — le dije a mozo.

— ¡Aviraneta!... ¡Aviraneta! Usted no me lo ha dicho así.

—Quizá me haya equivocado — dije, y pensé entre mí: "Con qué gusto le pegaría un puntapié a este imbécil". - -Vamos a ver dónde está.

-Armario tantos..., estante tantos..., número del legajo tantos... - - leyó.

Marchó el mozo, cogió un legajo, lo miré yo; no había nada de Aviraneta.

- ¿No nos habremos equivocado de número? — pregunté, y fui a ver el catálogo.

Efectivamente, el mozo se había equivocado de número, y en otro legajo estaba la hoja de servicios de Aviraneta.

-Déjeme usted leerla.

-No, no —me dijo- - Pida usted permiso al jefe.

Fui a ver al jefe, me escuchó como escuchan los empleados españoles, mirando a otra parte, y me dijo que esperara.

Esperé en la oficina.

Por fin, me dejaron tomar unos apuntes atropelladamente.

Luego he ido buscando más papeles y documentos, siempre con dificultades enormes, hasta rehacer casi por completo la vida de Aviraneta. Ha sido una labor casi de detective. Luego, para mí, lo difícil fue, después de reunir esta serie de datos, darles carácter literario. Sería cosa muy larga de contar todos los caminos que he seguido para buscar datos acerca de mi personaje y de la época.

Aviraneta no era un hombre culto, no había hecho estudios clásicos ni modernos. No tenía más que un talento natural, una inteligencia clara y amplia; suplía 
con la intuición los conocimientos que le faltaban. Tampoco era orador, y esto en su época y en la nuestra para ser político constituía una gran falta.

La vida de Aviraneta está llena de incidentes; tanto, que al escribirla no se puede hacer más que algo rápido y escueto.

En muchas cosas me he basado en hechos, en otras únicamente en indicios.»»

En lo que se refiere a las fuentes escritas, además del costoso trabajo de investigación en documentos y manuscritos que dormían en los archivos, Baroja contrajo la tarea de indagar y revisar los trabajos históricos anteriormente elaborados. En esta labor de investigador, Baroja fue completamente distinto a Galdós, que se vio impulsado a escribir con una prisa incontenible sus Episodios $\mathrm{Na}$ cionales, unas veces acosado por su situación económica, otras veces por sus compromisos políticos, siempre con una orientación demasiado ceñida a lo que fueron las corrientes políticas dominantes desde los partidos. El posicionamiento de Baroja fue el opuesto, y, a pesar de su escepticismo por el verdadero acontecer, su minuciosidad le llevó a la búsqueda incesante de vestigios fiables y a la verificación de los datos que utilizaba.

Incluso, para acercarse físicamente al pasado, al igual que antes había hecho al escribir muchas de sus novelas, Baroja continuó utilizando el procedimiento directo, de ascendencia naturalista, de trasladarse al lugar en que se había desarrollado el suceso, reconstruyéndolo allí paso a paso. Serán suficientes cuatro ejemplos:

Para escribir la aventura de Aviraneta en Laguardia, aventura que hace de prólogo a la serie de novelas, Baroja se trasladó a aquella población y vivió en ella por algún tiempo, hospedado en la misma posada en la que el personaje novelesco sufrió el asalto de los carlistas.

También, en cierto pasaje de sus $M e$ morias dice Baroja: «en 1914 yo anduve por la provincia de Burgos y creo que en esta época la vida sería en el campo muy parecida a la del tiempo del Empecinado, del cura Merino y Aviraneta. Estuve en Barbadillo del Pez, Barbadillo del Mercado, Salas de los Infantes, Arauzo de Miel, Huerta del Rey, Hontoria del Pinar, Peñaranda de Duero, etc... Algunos pueblos de éstos tenían que ser iguales a como eran hace un siglo. Otros, quizá peores...».

O cuando Baroja se dispuso a escribir las novelas que tenían como protagonista al conde de España, donde relata los últimos acontecimientos de la guerra carlista que tuvieron lugar en el Maestrazgo y Cataluña. Para lograr este objetivo, recorrió, en compañía de su sobrino Julio, aquella región, siguiendo en rigurosa peregrinación los caminos y vericuetos que atravesó el conde de España antes de ser asesinado.

El cuarto ejemplo lo tenemos en la referencia de Ortega y Gasset, donde, dando a conocer el viaje que el novelista realizó a Coria, dice que «desde hace mucho tiempo todos los pasos de Baroja van guiados por el espectro de Aviraneta» ${ }^{3}$.

\section{La Historia de España y la atracción por Aviraneta}

Decía Baroja en 1917, en el Nuevo tablado de Arlequín: «El que busque razonamientos o datos de la Historia para orientarse y ver si hay unidad o variedad en el tipo español a través del tiempo, se encontrará con que la Historia de España está por hacer. Se conoce, sí, una narración anecdótica de los reyes y sus familias; pero la vida de los pueblos y de las comarcas está en la oscuridad. No sólo los detalles, sino lo más fundamental, queda sin aclaración Así, por ejemplo, un proceso tan importante como el de la supuesta decadencia de España está sin resolver». 
En este contexto, Baroja intentó escribir una Historia de España capaz de esclarecer lo español, con protagonistas capaces de destacar de la vulgaridad de la masa amorfa a través de su genio y su carácter. Para ello necesitaba de un personaje dotado de una serie de cualidades capaz de impulsar los acontecimientos, un sujeto contradictorio, a la par que envuelto en un halo de misterio.

$\mathrm{Y}$ en el recuerdo de los Baroja existía un antepasado que detentaba estos atributos, una figura sobre la que hacían referencia los libros de historia.

Fernando de los Ríos, por ejemplo, dice que «Aviraneta vivió modestamente, escaso de fortuna, sin explotar los recursos que el Gobierno de Madrid puso a su disposición; prestó inmensos servicios, murió pobre y sin que se haya hecho la debida justicia a su abnegación, su patriotismo y su talento». Igualmente, Juan Rico y Amat, en su Historia política y parlamentaria de España, manifiesta: «Otro aventurero de talento, de más recursos, buscado y protegido por el ministro Pita, encargóse de minar por su base la causa carlista y de preparar la deseada transición. Nos referimos al hábil e ingenioso conspirador don Eugenio de Aviraneta, que tanto contribuyó a la realización del convenio de Vergara. Dotado de una sagacidad nada común, de extraordinaria travesura, de fecunda imaginación, salió Aviraneta...». También Antonio Pirala, en su Historia de la guerra civil, apunta que «pocos habrían ejecutado la difícil misión de Aviraneta con más acierto y desinterés: pues en vez de lucrarse en lo más mínimo, fue exiguo el gasto que hizo y devolvió el dinero que le sobró, aunque se le cedía. El desinterés y la honradez han sido siempre patrimonio de Aviraneta, uno de los hombres que más servicios han prestado a la causa liberal y a España. Su notable historia merece ser conocida» ${ }^{4}$.
Y al mismo tiempo, como hostigándole tenazmente, se alzaba toda una literatura en la que se tachaba a Aviraneta como traidor, oportunista, miserable...

Baroja ya tenía el protagonista con el que llegaría a formar la serie de 22 novelas escritas entre 1912 y 1934, reunidas bajo el enunciado general de Memorias de un hombre de acción.

Baroja dice que escribió sobre Aviraneta «porque era pariente mío»; hay sin duda una razón más profunda que ese lejano parentesco para explicar el interés y la atracción que sintió el novelista hacia la persona y la vida de Aviraneta, cuya figura, en el caso de las Memorias... ofrece más interés novelesco que histórico; éste —el histórico - quedará cumplido con la publicación de Aviraneta o la vida de un conspirador en 1931.

Es eso precisamente - lo novelesco prevalece sobre lo histórico- lo que define el carácter de la novela histórica barojiana frente a los Episodios Nacionales de Galdós. Si en Galdós la función de la ficción es servir de cimiento y de sostén para la materia histórica, que tiene, como tal, preferencia sobre lo novelesco. En Baroja sucede exactamente lo contrario. Partiendo de su poco aprecio o menosprecio hacia la historia como ciencia, con la figura de don Eugenio de Aviraneta, Baroja pretende demostrar que la novela permite un conocimiento de la realidad más profundo y perfecto que la historia. Así, la materia histórica es el trampolín que le permite a la fantasía creadora del novelista el salto al universo autónomo de la ficción, pero sin romper amarras con la realidad porque, a fin de cuentas, Baroja es un realista, aunque a veces él mismo no sepa definir con precisión su propio realismo.

En el prólogo de El aprendiz de conspirador dice Baroja: "Aviraneta era uno de esos hombres íntegros personalmente, que buscan los resultados sin 
preocuparse de los medios; Aviraneta era un político que creía que cada cosa tiene su nombre, y que no hay que ocultar la verdad, ni siquiera aderezarla». Y continúa apasionadamente: «Aviraneta quiso ser un político realista en un país donde no se aceptaba más que al retórico y al orador. Quiso construir con hechos donde no se construía más que con trapos. Y fracasó... Él vivió su época, con sus odios y sus cariños, con sus grandezas y sus roñerías, y vivió con intensidad.»

Baroja ya tenía el héroe a su medida, «el hombre que está por encima de la religión, de la democracia, de la moral, de la luz y taquígrafos..., queda el hombre, es decir, el héroe, que en medio de las tempestades, fe los odios, de los recursos de la mediocridad, de la envidia de los hombres cetrinos con las vejigas calculosas, impone una norma difícil a los demás; sí, queda el hombre, el héroe...». Y desde ese mismo momento se declaró decidido partidario de su personaje.

\section{La guerra carlista, época de conspiraciones}

Eugenio de Aviraneta, el conspirador, con un pie en la historia y otro en la leyenda, es el protagonista barojiano de la guerra carlista, al que acompañan otros personajes, entre literarios y aventureros, que consideraban que, mediante acciones audaces y creando confusión en las líneas enemigas, se podían conseguir avances que no se producían en los campos de batalla.

Aviraneta se había propuesto crear la división entre fuerzas carlistas. Con tal objetivo, comisionado por el ministro de la Gobernación Pío Pita Pizarro, se trasladó a la retaguardia carlista en Francia en 1837 para analizar la situación de dichas fuerzas y crear elementos de confusión entre ellas. Uno de sus métodos más socorridos consistía en difundir impresos en lengua vasca por el territorio ocupado por los carlistas, publicaciones donde procuraba encizañar a los vascos contra los castellanos, considerando a estos últimos ajenos y enemigos de los vascos («El Simancas»y «De agente del gobierno liberal» en Aviraneta o la vida de un conspirador).

También se encontraba por estas fechas en Francia, concretamente en Burdeos, el general Rafael Maroto, antiguo comandante en jefe en Vizcaya y en Cataluña, hasta que, en 1838, fue reclamado por don Carlos desde España para que se pusiera al mando del Estado Mayor. Según el historiador García Venero, Maroto, a su regreso, reorganizó el ejército, pagó los sueldos y abasteció a la intendencia. La tropa mostraba su entusiasmo por el nuevo jefe, cuya filiación era la de carlista moderado.

Mientras tanto, en la Corte de Estella una fracción apostólica, influyente y formada por Arias Tejeiro, el obispo Abarca, el de León, el general Uranga, González Moreno..., intrigó contra Maroto, al que sostenían, entre otros, el arzobispo de Cuba, fray Cirilo de la Alameda, Ramírez de la Piscina y el P. Gil.

Aviraneta, que tenía confidentes en el bando carlista, al conocer las disidencias en la corte de don Carlos, pensó alimentarlas. Mientras, los antimarotistas tomaron como pretexto una entrevista celebrada, a fin de canjear prisioneros, entre Maroto y un ayudante de Espartero, para lanzar el bulo de que estaba preparándose una traición contra don Carlos. Algunos escritores carlistas afirman que en dicha entrevista quedó concertada la clave de las comunicaciones entre Espartero y Maroto.

El conspirador, por tanto, no podía dejar escapar esta oportunidad y, para atizar y explotar la discordia, empezó a tejer una espesa red. Pudo enterarse que los generales Guergué, García, Sanz, Carmona y otros, de acuerdo con la camarilla 
apostólica, habían fraguado el fusilamiento de Maroto cuando éste llegara a Estella. Querían poner a don Carlos ante el hecho consumado.

Maroto, sin embargo, enterado de la conspiración contra su persona, se presentó en Estella con tres batallones navarros, aprehendió y mandó ajusticiar a los cabecillas del complot («La confidente y los fusilamientos de Estella» en Aviraneta o la vida de un conspirador). Así y todo, siendo visceral el antimarotismo del círculo apostólico, Aviraneta no cesaba en su empeño. Consideró, por tanto, que era preciso facilitar pruebas para que este sector tuviera facilidades en su empeño de acusar a Maroto de traidor, corrompido y masón. Y puesto que no había documentos auténticos, se dispuso a falsificarlos. Compuso un legajo o dossier apócrifo («El Simancas» en Aviraneta o la vida de un conspirador). Según la conspiración urdida por Aviraneta, un legitimista francés encontró, en el equipaje de un español, cierto legajo con documentos importantísimos para la causa carlista. El legitimista no quería que su nombre trascendiera y estaba dispuesto a prestar los documentos si le daba palabra de honor de que le serían devueltos.

A modo de anticipo, Aviraneta confeccionó varas planchas masónicas. Por lo visto no le resultaba difícil, ya que él mismo pertenecía con grado alto a la francmasonería del rito escocés. Hizo grabar un diploma masónico y lo llenó con el nombre de Rafael Maroto. El enlace francés visitó a don Carlos, quien pidió que le fuera enviado con rapidez el resto del legajo.

Mientras esperaba el estallido, nuestro conspirador, incansable, hizo fracasar un empréstito de quinientos millones de reales, concertado entre los carlistas y las casas de banca Tastet y Francessin.

Surgió de pronto una maniobra de Maroto, quien pretendía alcanzar para su proyecto el beneplácito francés y el británico. El general sugirió, al parecer, que Carlos María Isidro renunciase a favor de su hijo Carlos Luis y que éste casara con Isabel II. También se afirma que en los tratos con ingleses y franceses fue examinada la expulsión del infante y su familia del País Vasco y Navarra y la proclamación de una República vasco-liberal-clerical. (En este designio parece que se inspiró don Benito Pérez Galdós al escribir ciertas páginas, muy divertidas, que figuran en su episodio nacional Amadeo I.)

Esta maniobra de Maroto le pareció gravísima a Eugenio de Aviraneta y remitió con prisa el resto del legajo a don Carlos. En Tolosa -5 y 6 de agosto de 1839 - don Carlos y su ministro Marcó del Pont leyeron y creyeron en la veracidad del documento. Surgió el estallido previsto: don Carlos dispuso que el ejército se alzara contra Maroto.

Pero el pretendiente ignoraba cuál era el espíritu de las tropas. Los vizcaínos daban muestras de un gran desaliento y los guipuzcoanos se opusieron a cumplir la orden de don Carlos para que combatieran a las huestes del general. Es importante mencionar el hecho de que Rafael Maroto tuviera a su lado únicamente a generales vascos y a tropas vizcaínas y guipuzcoanas. Las alavesas no estuvieron presentes en el «Convenio de Vergara»y si también es cierto que en éste participaron mandos y fuerzas castellanas, hay que señalar que al infante le siguieron en su exilio numerosos soldados castellanos.

Más conspiraciones: José Antonio de Muñagorri y su proclama Paz y fueros

Otro personaje barojiano, relacionado con Aviraneta y que de algún modo fluye a su alrededor, fue Jose Antonio de Muñagorri Otaegui (1794-1841), autor de la proclama Paz y fueros y cuya pretensión fue acabar con la guerra carlista (1833-1839) 
enarbolando la bandera foral. Para dar mayor publicidad a sus propósitos, hizo circular en forma de bertso paperak (hojas volanderas) una colección de veinte coplas (aunque también existe otra remesa complementaria de otras diecisiete estrofas) que bajo el epígrafe de Berso berryak, egui garbiyak (coplas nuevas, verdades sinceras) se divulgaron y cantaron en los pueblos navarros y guipuzcoanos y entre los batallones carlistas, principal objetivo de su propaganda. Esta colección de coplas es conocida popularmente con el nombre genérico de Muñagorriren kantak (Las coplas de Muñagorri).

Si bien Muñagorri no fue el autor material de estas estrofas, sí fue su inductor intelectual. Para ello, siguiendo la costumbre de la época de difundir en forma de coplas los acontecimientos más sobresalientes, encargó su realización a algún bertsolari (coplero, improvisador de versos) que, si nos atenemos al dialecto utilizado, debía proceder de los alrededores San Sebastián, poblaciones como Usurbil, Astigarraga, Hernani o Asteasu.

Siguiendo las consignas de Muñagorri, en las coplas no se escatiman epítetos al referirse a la contienda carlista, con expresiones como "Carlos agertu ezkero probintzi auetan, beti bizi gerade neke ta penetan» (Desde que Carlos apareció por estas provincias, siempre vivimos con penas y trabajos), "Gerrak ondatzen gaitu bostgarren urtian» (La guerra nos arruina hace cinco años), "Gerrak ez dakar onik iñundik iñora» (La guerra no trae nada bueno para nadie, por ninguna parte), "Ainbeste odol ixurtze ez da doloria? Il da probintzi autan gaztien loria» (¿No es pues doloroso tanto derramar sangre? La flor de los jóvenes ha muerto en estas provincias), "Anaya anayen kontra txit gauza tristia!» (Triste cosa es la lucha de hermano contra hermano).

El principal interés de estas coplas reside en que reflejan profundamente el estado de opinión que reinaba en el País y del que carecen las historias oficiales.

A la muerte de Fernando VII, el pronunciamiento carlista proclama Rey a Carlos M. ${ }^{a}$ Isidro en Vitoria y Bilbao en 1933, pero, después de unas primeras victorias fulgurantes, tras el contraataque del ejército liberal-cristino dirigido por el mariscal Sarsfield, los carlistas fueron abandonando las ciudades y replegándose a los pueblos y partes más montañosas del País Vasco y Navarra, donde se mantuvieron fuertes durante seis años.

Por ello, a medida que los carlistas fueron ocupando estas zonas del territorio, sus autoridades y pobladores no pudieron menos que colaborar con las huestes carlistas, como es el caso de Berastegi (Guipúzcoa), población en la que Muñagorri ejercía de escribano, aunque éste, tanto por formación como por inclinación política, era más proclive a la causa liberal.

Con la extensión de las hostilidades las dificultades económicas se fueron agravando, mientras la contienda, sin perspectivas y convertida en una guerra de desgaste, estaba totalmente estancada. $\mathrm{Si}$ en el bando liberal las fisuras son manifiestas, la expedición carlista a Madrid será absolutamente inoperante. La situación es cada vez más grave y las consecuencias son patentes entre la población. El mismo Muñagorri, inmerso en labores de intendencia, sufre graves percances monetarios, no pudiendo hacer frente a las deudas contraídas con ferrones, arrieros, carboneros y demás jornaleros.

En marzo de 1837 un batallón carlista se apoderó de la fortaleza de Oriamendi en San Sebastián, aunque finalmente no pudieron controlar dicha ciudad. Esta derrota produjo un gran desasosiego entre las fuerzas liberales, donde va tomando fuerza la idea de que sería muy difícil 
derrotar a los carlistas en el campo de batalla, por lo que se imponía recurrir a otros procedimientos, tanto diplomáticos como políticos.

Muñagorri coincidía plenamente con estos movimientos alternativos. Siguiendo el relato de Antonio María Labayen, Muñagorri, situado en el campo carlista, ya había hecho gestiones anteriormente ante personajes de la Junta carlista. Paralelamente había mantenido contactos con sus amigos liberales del otro bando, a los que era bastante fácil acceder desde Berastegi, en donde tuvo mayor acogida que entre los jefes carlistas. Su propuesta fuerista habría sido bien recibida por significados liberales como el Marqués de Alameda, Conde de Villafuertes, Monterrón, Uhagón, Vidarte y Arnao.

Estas coplas, imprimidas en las prensas de la Casa Baroja de San Sebastián el año 1838, constan de treinta y siete estrofas (a modo de dos versiones, uno de veinte estrofas y otro de diecisiete) en versos alternos de siete y seis sílabas rimando los versos pares. Probablemente fueron A continuación, voy a reproducir algunas de ellas en su grafía original:

\section{Muñagorric diona \\ Bere proclamian \\ Guerrac ondatzen gaitu \\ Bost garren urtian; \\ Ygaz jarrisan Carlos \\ Madrilco vidian \\ Bultza zuten atzera, \\ Guerra vere oñian.}

(Como dice Muñagorri en su proclama, la guerra nos arruina desde hace cinco años. El año pasado Carlos se encaminó hacia Madrid; le han hecho volver atrás, la guerra le pisa los talones)

\section{Aguintari onenac \\ Preso daduzcate \\ Euscalduna izatia \\ Du bacoitzac calte;}

Tejeiro ta Maroto

Gucien alcate

¿Cer guizon oyetatic

Espera guentzaque?

(Los mejores jefes están presos, ser vasco es un perjuicio para cada uno. Tejeiro y Maroto son los dueños de todos, ¿qué podemos esperar de hombres así?)

\section{Carlos aguertu ezquero \\ Provinci auvetan \\ Beti vici guerade \\ Neque ta penetan: \\ Maiz quendu guc deguna \\ Beñere ecer eman \\ Bost negar eguiteco \\ Numbait jayo guiñan.}

(Desde que Carlos apareció por estas provincias, siempre vivimos con penas y trabajos. Aunque nos quitan lo nuestro, nunca nos dan nada: por lo visto, hemos debido nacer para enjugar abundantes lágrimas)

\section{Semiac soldatu ta \\ Preso gurasuac \\ Eciñ pagaturican \\ Contribucioac; \\ Trinchera lanetara \\ Gañera ausuac \\ Dolorescoac dira \\ Gaur gure pausuac.}

(Los hijos soldados y los padres presos, sin poder pagar los impuestos. Los vecinos [son llamados] a los trabajos de trincheras; son tristes nuestros destinos)

\section{Cordois inguraturic \\ Costatic Ebrora \\ Trabas josiric gaude \\ Bera eta gora \\ Atzenican franzesac \\ Ychi du frontera \\ Guerrac ez dacar onic \\ Yñundic iñora.}

(Nos tienen acordonados desde la costa al Ebro; por todas partes nos cercan las dificultades. Por último el francés ha cerrado la fronte- 
ra; la guerra no trae nada bueno para nadie, por ninguna parte)

Atiac ichi eta
Oguia garesti
Artua ere aida
Ygotzen poliqui
Diruba escutatzenda
Egunero emendi,
Nola bici gueraren
Arritutzen naiz ni

(Las puertas cerradas y el pan caro; también el maíz ha empezado a encarecer; el dinero se esfuma cada día de aquí; me asombra cómo vivimos)

\section{¿Ainbeste odol ixurtze \\ Ezta doloria? \\ Ylda provinci autan \\ gaztien loria. \\ Patria defenditzea \\ Litzake honoria; \\ iAnaya anayen contra \\ Chit gauza tristia!}

¿No es, pues, doloroso derramar tanta sangre? La flor de los jóvenes ha muerto en estas Provincias. Sería honroso defender a la Patria. Triste cosa es la lucha de hermano contra hermano)

Oraiñ seieun urte
Guchi gora bera
Gastelako Reinura
Unituak gera,
Gastelan cein buru dan
Ura guc artzera,
Fueroak gordezquero
Egintzan paperan.

(Nos unimos hace 600 años más o menos al reino de Castilla. Se firmó en los documentos que aceptaríamos al dirigente de Castilla, sea el que fuese, con tal de que guardase los Fueros)

\section{Disputaturican bada \\ Ceiñentzat coroa \\ Erabaqui bear da \\ Gastelan pleitua.}

\author{
Erregue edo Erreguiña, \\ Gure derechua \\ Beti gorde digula \\ Garbiro fuerua.
}

(En Castilla se ha de decidir, caso de haber disputa, a quién corresponde la Corona; con el Rey o con la Reina, nuestro derecho se ha de acatar, y que nos respete completamente el Fuero)
Potenci indarsubac
Eman dute itza;
Eguiteco baquiac
Prestuak dabiltza.
Provinciac baquean
Daduca vicia
¿Norc eztu bere amaren
Sendatu nai gaitza?

(Las Potencias poderosas han dado su palabra; se están moviendo para lograr la paz. En la paz está la vida de la Provincia. ¿Quién no quiere sanar el mal de su madre?)

Hay que señalar que el gesto de $\mathrm{Mu}-$ ñagorri causó gran consternación en el País Vasco y Navarra. Si era cierto que contaba para su proyecto con el beneplácito y la ayuda económica del Gobierno de Madrid, así como del grupo de dirigentes liberales fueristas antes citados, a los que habría que añadir prestigiosos nombres guipuzcoanos como Olano, Egaña, Berroeta o Palacios, su mayor fuerza residía en que sintonizaba con las ansias populares y el anhelo de paz general.

El proyecto de Muñagorri, presentándose como una tercera alternativa, sembró la desconfianza entre los carlistas, por lo que fue combatido con indignación y dureza por éstos, cuyo proyecto amenazaba reclutar partidarios a costa de aumentar las deserciones en dicho bando. El procedimiento ideado por Muñagorri dio sus frutos hasta que, perseguido por el carlista Iturbe, tuvo que internarse en Francia, donde, con un millar de hombres, se instaló en un campamento fortificado, junto al Bidasoa, en Lastaola, entre 
Behobia y Endarlaza, en la frontera con Navarra y Francia. En estos quehaceres Muñagorri contó con el apoyo de Gaspar de Jáuregui, Artzaia, caudillo popular en la insurrección vasca contra la invasión napoleónica de 1808, y del comodoro inglés lord John Hay.

Entre los sectores del clero que apoyaban su iniciativa hay que señalar al sacerdote Pascual Iturriaga, amigo de Muñagorri y probablemente asesor literario de las proclamas y coplas divulgadas por éste. Asimismo, no sería aventurado afirmar que este clérigo también fuese el autor, en su versión euskérica, de las proclamas, alocuciones y documentos emitidos por Espartero.

La actividad militar del contingente formado por Muñagorri fue muy reducida, si bien realizaron algunas incursiones, siempre propagandísticas, contra las huestes carlistas desde la base de Lastaola. Por su parte, las autoridades carlistas respondieron acusando a Muñagorri de sedición, embargando sus bienes y destituyéndole de su cargo de escribano real.

Otra conspiración, alentada por Aviraneta y relacionada en parte con Muñagorri, fue la que pretendía secuestrar al infante don Carlos, a primeros de 1839 («Un proyecto de secuestro de Don Carlos» en Aviraneta o la vida de un conspirador). Por estas fechas Bayona era un centro de espionaje e intriga, fraguándose proyectos y conjuras para dar fin a la guerra, bien fuera por la traición o por el engaño. Se mascaba un próximo desenlace tras los fusilamientos ordenados por Maroto en Estella (Navarra). Uno de estos proyectos, cuyos mentores intelectuales procedían del bando liberal progresista donostiarra, era el rapto del pretendiente D. Carlos Isidro, que a la sazón había establecido su cuartel general en Azkoitia (Guipúzcoa). Aviraneta sometió su plan al general Gaspar Jáuregui, Artzaia (Pastor) y a Lorenzo de Alzate y Domingo
Orbegozo, colaboradores suyos. Artzaia declaró que disponía de un hombre capaz de realizar con fortuna la gran aventura. Era un sargento de «chapelgorris» (boinas rojas) llamado Ramón Elorrio.

Enterado Aviraneta que el pretendiente carecía de numerosa guardia cuando las tropas realizaban operaciones o marchas, un grupo de soldados capitaneados por el mencionado sargento de chapelgorris (también llamados peseteros por que su paga estaba estipulada en una peseta diaria) raptarían al infante y a su hijo Carlos Luis, llevándoles a la cercana costa de Zumaia (Guipúzcoa), donde les esperaría una fragata inglesa al mando del citado comodoro John Hay. En los preparativos de esta misión formaron parte hombres de confianza de Muñagorri.

Finalmente se desistió realizar esta misión, aunque el sargento Elorrio, ferviente esparterista que después de la contienda fue ascendido a teniente por sus servicios, siempre consideró a Muñagorri como el inductor del abandono de este proyecto. Para Antonio María Labayen, a raíz de este acontecimiento, Elorrio contrajo un gran rencor y animadversión hacia Muñagorri.

Así, dos años más tarde, el 14 de octubre de 1941, Ramón Elorrio se presentó con un grupo de soldados en la ferrería de Muñagorri en Erasun (Navarra), quien, apresado sin que opusiera resistencia, fue conducido a un altozano llamado Pillota-Soro y fusilado a continuación. Respecto al cabecilla ejecutor, Elorrio, huyó más tarde a América sin que se tengan más noticias de su paradero.

El día siguiente a la muerte de Muñagorri su cadáver fue conducido a Erasun en cuya iglesia parroquial se celebraron funerales. Sus restos mortales fueron enterrados en la misma iglesia y allá reposan hoy en día ${ }^{5}$. 


\section{A modo de conclusión. "El hombre de acción», protagonista de la novela histórica barojiana}

¿Hasta qué punto Aviraneta, el héroe de las Memorias de un hombre de acción, es el hombre de carne y hueso, antepasado suyo, que nació en Madrid, creció en Irún, que luchó contra los franceses a las órdenes del cura Merino, más tarde con el Empecinado y viajó por América, por Egipto y por Grecia y fue masón, carbonario, cerebro de la «La Isabelina», que fue creador del «Simancas», instigador de estrategias con la finalidad de engendrar malestar y división entre fuerzas carlistas, colaborador necesario del «Convenio de Vergara»... y otras muchas peripecias?

Evidentemente, el Aviraneta de la Memorias de un hombre de acción es un personaje de Baroja, fiel reflejo del perfil del aventurero buscado y retratado por el novelista, hermano de Chimista, de Juan de Aguirre, de Zalacaín, etc. Baroja, sin duda alguna, pretendió acercarse Aviraneta, y efectivamente lo logró; pero es igualmente incuestionable, como acertadamente formula Flores Arrayuelo «que este personaje suyo, figura reconstruida e intuida por la estela de datos y de recuerdos que quedaban, fue acoplándose a un personaje que llevaba en sí el novelista y que recibía el nombre de "hombre de acción" (...) Y Baroja, consciente e inconscientemente, atrajo hacia sí a la figura de su personaje aventurero, el Aviraneta de carne y hueso» ${ }^{6}$.

El hombre de acción aparece dominado por un dinamismo que contrasta fuertemente con la quietud contemplativa de los personajes místicos que podemos encontrar en otras obras del novelista. Es el personaje que Baroja necesitaba para escribir las novelas históricas del siglo XIX español. Su genio y temperamento recorre la columna vertebral de la obra barojiana, y está permanentemente invo- cada por el novelista. Citaré tres fuentes como ejemplo, aunque todas remiten al mismo origen.

Pedro Leguía, imaginario pariente de Baroja, criatura hecha a imagen y semejanza del escritor, y al que su autor atribuye la función de transcribir los cuadernos de las Memorias de un hombre de acción, describe en El aprendiz de conspirador el ideal del hombre de acción, cuya manera de ser le lleva a: «andar y andar tierras, divisar nuevos horizontes, cambiar de paisajes, comer aquí, dormir allá..., no volver nunca mirada atrás».

También el propio Aviraneta, en $E l$ escuadrón del Brigante, relatando sus correrías por tierras de Castilla, manifiesta su desdén por la pasividad contemplativa: «Un amante de la naturaleza se habría quedado absorto contemplando el ruinoso convento, próximo al riachuelo espumoso, con su torreón cuadrado, su fuente en medio y sus viejas tumbas de guerreros. Yo confieso que a mí estas cosas no me han entusiasmado nunca. El contemplar pasivamente no está en mi temperamento».

Por último, el propio Baroja subraya con rotundidad la recompensa que brinda este modo de existencia: «En apariencia, la vida de un hombre de acción es un juego de azar, una lotería en la que se emplea mucho dinero, y sólo de tarde en tarde toca un premio pequeño; en realidad, la vida de un hombre de acción, si es una lotería, es una lotería que toca siempre, porque el jugador lleva el mayor premio en el máximo esfuerzo. La acción por la acción es el ideal del hombre sano y fuerte; lo demás es parálisis que nos ha producido la vida sedentaria» ${ }^{7}$.

Y de la mano de este recreado protagonista, Baroja recorrerá el territorio español, se adentrará en su historia y reflexionará sobre su presente, y su valoración no puede ser más negativa: «las ideas han sido un pretexto: la legitimi- 
dad, la religión, cierta tendencia de separación en las pequeñas naciones abortadas como Vasconia y Cataluña; pero en el fondo barbarie. Después de estos fulgores de locura y de fanatismo, como un cuerpo enfermo después de la fiebre, España ha quedado casi muerta, y el individualismo se ha ensanchado de tal manera, que se nota en la sociedad. Desde que la iglesia ha perdido su asentimiento universal, tomo el mundo tira a Robinsón en esta tierra. El pobre se muere en un rincón sin ninguna ayuda; el rico se encierra en su propiedad a tragarse lo que tiene sin ser visto; el obispo ahorra su sueldo para la familia, y el cura recoge las migajas del suelo. De tragadores ahítos y de lameplatos hambrientos sin placer y sin gusto, de esta clase de gente se compone hoy España. Nuestra tierra es un organismo desangrado y anémico, no por esta guerra, sino por trescientos años de aventuras y de empresas políticas. Es, además, país pobre, sin ríos navegables, sin lluvia suficiente. Es lo primero que debía reconocer España ante el mundo, que es un pueblo pobre, zarrapastroso, que se zafa de todos los compromisos y que quiere vivir para él sólo. Nuestra casa es una casa mísera que ha gastado mucho y tiene que vivir ahora en la máxima estrechez... En los pueblos no hay necesidad, no hay jardines, no hay libros, no hay religión, no hay amores, no hay complicaciones, no se come ni se bebe bien. España no tiene cabeza. Madrid no se nota apenas en las provincias, y las provincias no notan Madrid más que cuando hay asonadas o pronunciamientos. Se ve que nuestro país es un cuerpo débil, con la cabeza débil» ${ }^{8}$.

Baroja se revela con Aviraneta ante un país que ha perdido su conciencia, que se ha acostumbrado a las mentiras convencionales y rinde culto a la admiración interesada por el prójimo. Y, paralelamente, exalta al genio que no se somete a la moda y glorifica el esfuerzo laborioso de la actividad creadora, que luchando contra los obstáculos, aumenta y desarrolla las virtudes y capacidades espirituales.

No es de extrañar, en este aspecto, que Baroja asocie a Aviraneta con Robespierre: «Aviraneta era un Robespierre sin sostén social, sin partidarios, amargado, ácido, después de haber recorrido el mundo y haber conocido la miseria y la inquietud en todas sus formas. Era un Robespierre de España, de un país pobre, áspero, desabrido, frío y sin efusión social. El furor lógico del sombrío Maximiliano lo reemplazaba Aviraneta con la rabia, con el despecho, con el cólera y, sobre todo, con el desprecio de los hombres» ${ }^{9}$.

Aviraneta, por tanto, es el síntoma de esta incapacidad de transformación. Toda una concepción del mundo se agotaba en España, pero su desenlace se estaba prolongando demasiado. Aún no contaba la idea de nación y la burguesía no era fuerte económicamente. Se fraguaba el proyecto que lograra pasar de la sociedad estamental a la sociedad burguesa, para lo que no faltaban propuestas, aunque todas estériles. Tampoco se sabía cómo terminar con los elementos inertes para el desarrollo de la sociedad, simbolizados en la aristocracia y en el clero regular.

Flores Arroyuelo ${ }^{10}$ ha analizado las reflexiones que hace Baroja sobre el carácter de la generación que tenía ante sí el reto de la transformación que exigía la sociedad española, una de cuyas manifestaciones fue el protagonismo que asumió el Ejército a través de su larga cadena de pronunciamientos, pero cuyo verdadero motor fue el afán de poder personal de mucho de los militares: «Ni por las ideas, ni por el temperamento, se podía saber con claridad quiénes eran los liberales y quienes los reaccionarios. La envidia y la intriga lo dominaban todo; por cuestiones personales cambiaban la política los militares y los paisanos» ${ }^{11}$. 
El talante de esta generación, según Baroja, es resultado inmediato del proceder que caracterizó a la generación anterior, con su indecisión y su fanatismo. Baroja, como tantas veces, nos habla de ello a través de Aviraneta: «Cuando veo de desde lejos mi época, comprendo que nuestro carácter, al mismo tiempo cuco e insensato, ha sido la causa de muchas desdichas. En España no es íntegramente el pueblo el difícil de dirigir, sino el cabecilla, el letrado, que es casi siempre egoísta, petulante y orgulloso. En la guerra civil pasada (se refiere a la primera guerra carlista), como en la guerra de la independencia; pero en esta última había una pasión que nos unía a todos. El español destacado no acepta fácilmente la colaboración de nadie: Parece decir en su fuero interno: $\mathrm{O}$ te sometes tú o me someto yo, pero no podemos marchar juntos» 12 .

Como sentencia Flores Arroyuelo ${ }^{13}$, un mundo terminaba, pero el cambio llegaba con retraso para España. El pueblo se había desangrado luchando contra los franceses en la Guerra de la Independencia, pero no tenía conciencia de nacionalidad ni sentido revolucionario para fijar la línea a seguir en el futuro. Y la discordia se impuso entre los españoles.

Por un lado, los revolucionarios atribuyeron al pueblo una madurez política y le otorgaron el derecho a elegir a sus representantes. Por otro lado, los tradicionalistas defendieron lo contrario argumentando que el pueblo se había alzado contra las nuevas ideas que venían de fuera, que había luchado contra lo extranjero en defensa de la genuina forma de vida tradicional española.

Los personajes de las novelas que componen Las Memorias de un hombre de acción son actores de esta generación, de ese tiempo tan confuso y enmarañado. Pedro Leguía, el alter ego de Baroja durante ese período, resume el carácter y la tragedia de su desdichada generación, todo un veredicto sobre el comportamiento humano: «Las generaciones han ido moldeando nuestros instintos, lo consciente y lo inconsciente; les ha dado una norma, un sentido; pero en este conglomerado de nuestra personalidad, la inteligencia se ha separado de sus viejos compañeros y ha empezado a marchas sola. Así, nuestra época ha dado, más que ninguna otra, santos sin ideas religiosas, ateos místicos, mujeres honradas con alma de cortesana y cortesanas con aspiraciones de monjas. Ante esta disociación de su personalidad, el hombre, que antes que nada quiere crear y poner un pie firme sobre la tierra, mira a su alrededor, y cuando encuentra una ruta la va siguiendo. Sus antepasados no escogían, se dejaban llevar, los hombres actuales escogen, y de ahí su desgracia. Unos escogen ciega y brutalmente - la mejor manera de escoger - ; otros, miran y remiran a derecha e izquierda, quieren pesar el pro y el contra, ¡los ilusos! Y cuando se deciden van, como los demás, a ciegas y siguen la estela que dejaron las grandes corrientes sentimentales pasadas» ${ }^{14}$.

\section{BIBLIOGRAFÍA}

Antxustegi Igartua, E. (2000): «José Antonio de Muñagorri: de coplas, guerras y conspiradores», biTARTE n..$^{\circ} 21$, agosto, San Sebastián.

- (2001): «Muñagorriren bertsoak o el fuerismo popular», Papeles de opinión LANDAZURI, números 8-9-10, julio, Vitoria.

BAROJA, Pío (1912): El aprendiz de conspirador, Renacimiento, Madrid. También en Ed. Espasa-Calpe, 1931 y 1991, y en Ed. Caro Raggio, 1976.

- (1913): El escuadrón del Brigante, Renacimiento, Madrid. También en Rafael Caro Raggio (1921): Ed. Espa- 
sa-Calpe, 1937, y en Ed. Caro Raggio, 1976.

- (1917): Nuevo tablado de Arlequín, Rafael Caro Raggio, Madrid. También en Ed. Caro Raggio, 1982.

- (1918): Las horas solitarias: notas de un aprendiz de psicólogo, Rafael Caro Raggio, Madrid. También en Ed. Caro Raggio, 1920 y 1982.

- (1919): La caverna del humorismo, Rafael Caro Raggio, Madrid.

- (1919): La caverna del humorismo, Rafael Caro Raggio, Madrid.

- (1927): Entretenimientos (dos sainetes y una conferencia), Caro Raggio, Madrid.

- (1931): Aviraneta o la vida de un conspirador (Vidas españolas e hispanoamericanas del siglo XIX), Espasa-Calpe, Madrid. También en Ed. Espasa-Calpe, 1947, y Ed. Caja de Ahorros Provincial de Guipúzcoa, 1972.

- (1944): El escritor según los críticos (Desde la última vuelta del camino, Memorias, 1), Biblioteca Nueva, Madrid.

- (1946-1951): Obras completas, 8 volúmenes, Biblioteca Nueva, Madrid.

- (1948): La intuición y el estilo (Desde la última vuelta del camino, Memorias, 5), Biblioteca Nueva, Madrid.

- (1979): «Memorias de un hombre de acción», Obras Completas, tomos III, IV, Biblioteca Nueva, Madrid.

CAro Baroja, J. (1972): «Confrontación literaria a las relaciones de dos novelistas, Galdós y Baroja», en Cuadernos Hispanoamericanos, n. ${ }^{\text {os }}$ 265-267, pp. 160-168, Madrid.

Castillo Puche, J. L. (1952): Memorias intimas de Aviraneta o Manual del conspirador (réplica a Baroja), Biblioteca Nueva, Madrid.

Flores Arroyuelo, F. J. (1971): Pío Baroja y la historia, Helios, Madrid.
García Venero, M. (1969): Historia del nacionalismo vasco, Editora Nacional, Madrid.

INTZAGARAI, R. (1933): «Muñagorrin kantak», Revista Internacional de Estudio Vascos, 24.

LABAyen, A. M. (1975): Muñagorri, su exposición a D. Carlos y sus famosas coplas de propaganda «Bertso Berriak», Tolosa.

- (1976): Muñagorri, escribano, pacificador y fuerista, Sociedad Guipuzcoana de Ediciones y Publicaciones, San Sebastián.

LARRE, J.-P. (1995): Muñagorri (1791-1841). Paix eta fueros. Aux origines $d u$ nationalisme basque, J\&D Editions, Biarritz.

LAsagabaster, J. M. (1989): «Pío Baroja» [actas de las III Jornadas Internacionales de Literatura, 11-15 de abril de 1988], en Mundaiz. Cuadernos universitarios, n. ${ }^{\circ}$ 7, 264 pp., Universidad de Deusto, Facultad de Filosofía y Letras, San Sebastián.

- (1991): «Introducción», en BAROJA, Pío, Paradox Rey, Espasa-Calpe, 12. ${ }^{\text {a }}$ ed., pp. 9-54, Madrid.

- (1998): «Baroja: El carnaval de la escritura (A propósito de La leyenda de Juan de Alzate)», en Ínsula. Revista de letras y ciencias humanas, n. ${ }^{\circ} 617$, pp. 27-29, Madrid.

- (1998): «Pío Baroja y la novela histórica: Estrategias narrativas en las Memorias de un hombre de acción», en Mundaiz. Cuadernos universitarios, n. ${ }^{\circ}$ 56, p. 9, Universidad de Deusto, Facultad de Filosofía y Letras, San Sebastián.

Longhurst, C. A. (1974): Las novelas históricas de Pío Baroja, Guadarrama, Madrid.

- (1998): «La novela histórica de Baroja. Las memorias de un hombre de acción, un género problemático», en 
VArios, Los Baroja. Memoria y lección, Fundación Kutxa, San Sebastián.

Michel, F. e Irigaray, A. (1963): Poesías populares de los vascos, vol. I, Auñamendi, San Sebastián.

Ortega y GAsset, J. (1963): El espectador, Colección «El Arquero», tomo I, Revista de Occidente, Madrid.

PÉrez GAldós, B. (1943): Episodios Nacionales: Amadeo I, Ed. Hernando, Madrid.
SÁnchez Ostiz, M. (2006): Pío Baroja a escena, Espasa-Calpe, Madrid.

VARIOS (1998): «Los Baroja», Memoria y lección, Fundación Kutxa, San Sebastián.

Zavala, A. (1993): Karlisten lenengo gerrateko bertsoak (1833-1839), Auspoa, Oiartzun.

\section{NOTAS}

1 O.c., VII, 436. Baroja se refiere sin duda a Zugarramurdi, pueblecito navarro en la frontera francesa de Dantxarinea, que tuvo un papel destacado en la historia de la brujería vasca.

2 Pío Baroja, La intuición y el estilo (Desde la última vuelta del camino, Memorias, 5) pp. 257-258, citado por Flores Arrojuelo.

3 Ortega y Gasset, El espectador, t. I, p. 105, citado por Flores Arrojuelo.

4 Estos autores y sus estudios históricos están citados por Flores Arrojuelo (1971: 66-67).

5 Para profundizar sobre este convulso período histórico, ver Esteban Antxustegi Igartua: «Jose Antonio de Muñagorri: de coplas, guerras y conspiradores», biTARTE, n. ${ }^{\circ}$ 21, agosto de 2000, San Sebastián, $\mathrm{y}$, también del mismo autor, «Muñagorriren bertsoak o el fuerismo popular», Papeles de opinión LANDAZURI, números 8-9-10, julio de 2001, Vitoria.

${ }^{6}$ Flores Arrojuelo, F. J. (1971: 198-199).

7 Pío Baroja, Obras Completas, t. III, p. 578, citado por Flores Arrojuelo.

8 Pío Baroja, Obras Completas, t. IV, pp. 442-443, citado por Flores Arrojuelo.

9 Pío Baroja, Obras Completas, t. III, pp. 1046-1047,

10 Op. cit.

11 Pío Baroja, Obras Completas, t. IV, p. 1041, citado por Flores Arrojuelo.

12 Pío Baroja, Entretenimientos (dos sainetes y una conferencia), p. 133, citado por Flores Arrojuelo.

13 Op. cit.

14 Pío Baroja, Obras Completas, t. III, p. 907, citado por Flores Arrojuelo. 